\title{
1 Hair phenotype diversity across Indriidae lemurs
}

2

$4 \quad$ Irwin $^{3}$, Jason M. Kamilar ${ }^{4,5}$, Brenda J. Bradley ${ }^{1}$

5

7 George Washington University

$8 \quad{ }^{2}$ Conservation Genetics Department, Omaha’s Henry Doorly Zoo and Aquarium

$9 \quad{ }^{3}$ Department of Anthropology, Northern Illinois University

10

${ }^{4}$ Department of Anthropology, University of Massachusetts Amherst

$11{ }^{5}$ Graduate Program in Organismic and Evolutionary Biology, University of Massachusetts

12 Amherst

13

$14 \quad *=$ Corresponding author:

15

16

17

18

19

20

21

22

23

24

25

26

27

28

29

30

31

32 


\section{Abstract}

Hair (i.e., pelage/fur) is a salient feature of primate (including human) diversity and evolution - serving functions tied to thermoregulation, protection, camouflage, and signalingbut wild primate pelage biology and evolution remain relatively understudied. Specifically, assessing multiple hypotheses across distinct phylogenetic scales is essential but is rarely conducted. We examine whole body hair color and density variation across the Indriidae lemurs (Avahi, Indri, Propithecus) — a lineage that, like humans, exhibits vertical posture (i.e., their whole bodies are vertical to the sun). Our analyses consider multiple phylogenetic scales (familylevel, genus-level) and hypotheses (e.g., Gloger's rule, the body cooling hypotheses). Our results show that across the Indriidae family, darker hair is typical in wetter regions (per Gloger's rule). However, within Propithecus, dark black hair is common in colder forest regions, which may implicate thermoregulation and is the first empirical evidence of Bogert's rule in mammals. Results also show pelage redness increases in populations exhibiting enhanced color vision and may thus aid conspecific communication in forested environments. Lastly, across Indriidae, we find follicle density on the crown and limbs increases in dry and open environments - rare empirical evidence supporting an early hypothesis on hominin hair evolution. We find an effect of body size on hue (red hair) and hair density but not on brightness (black hair). This study highlights how different selective pressures across distinct phylogenetic scales have likely acted on primate hair evolution. Lastly, since hair does not fossilize, the results of follicle and hair density variation across this clade offer us some potential insight into contextualizing human hair evolution.

Keywords: lemurs, coloration, sifaka, opsins, integument, adaptation 


\section{Introduction}

Hair (i.e., pelage, fur) is a salient feature of primate diversity and evolution and is the product of natural and sexual selection. Hair has been found to play a role in conspecific signaling (Allen and Higham, 2013), thermoregulation (Fratto and Davis, 2011), camouflage (Hoekstra et al., 2005; Barrett et al., 2019), and to possibly provide protection from pathogens/parasites (Paus \& Foitzik, 2004). Across all mammals, primates_-including humansarguably exhibit the most diversity in hair color (e.g., bright reds) and growth patterns (e.g., mustaches) between and within species (Rowe, 1996; Caro, 2005). For example, within Colobinae, some Colobus spp. sport a long black and white dorsal cape, and Pygathrix spp. are often tri-colored and short-haired (Rowe, 1996). Similarly, human hair color and texture vary throughout the human body, between individuals, between populations, and can be correlated with ancestry and ethnicity (Steggerda and Seibert, 1941; Seibert and Steggerda, 1999; Lasisi et al., 2016). Nevertheless, our knowledge about hair evolution is based mainly on non-primate mammals. Primate hair remains relatively understudied (with some notable exceptions: e.g., (Santana et al., 2012; Allen and Higham, 2013; Kamilar et al., 2013; Rakotonirina et al., 2017; Bell et al., 2021)), with most research taking a macro-scale approach and sampling broadly across the primate order (e.g., all catarrhines).

These previous studies indicate that variation in primate hair color likely evolved in response to multiple distinct but not mutually exclusive pressures associated with ecology, visual systems, activity cycles, and sociality (Santana et al., 2012; Allen and Higham, 2013; Kamilar et al., 2013; Rakotonirina et al., 2017; Bell et al., 2021). For example, across primates, melanic

(i.e., black) colors often co-occur with humid regions - which may be due to camouflage, 6 pleiotropy, pathogen resistance, or selection on a related trait (i.e., Gloger's rule) (Kamilar and 
47 Bradley, 2011; Santana et al., 2012, 2013; Bell et al., 2021). However, without accounting for variation within families, genera, and species, other subtle trends or relationships may not be detected. For example, recent work in birds suggests a distinct rule (Bogert's rule) may explain some melanic variation in endotherms depending on the phylogenetic and geographic scale sampled (Bogert, 1949; Delhey et al., 2019). According to Bogert's rule, melanic colors should co-occur with cold regions as dark colors may absorb heat better and aid in thermoregulation (Bogert, 1949; Delhey et al., 2019). However, there is no current empirical evidence for this rule

54 in primates (or any mammals). Yet across human populations, variation in eumelanin exceeds that seen in red, blonde, or lighter hair (Lasisi et al., 2016), which suggests that important biological variation may be identified if the scale of analyses was smaller than previously

57 considered (i.e., within a few populations vs. across all populations) (Norton et al., 2016). conspecific communication (Santana et al., 2012, 2013; Cuthill et al., 2017; Winters et al., 2019). For example, diurnal activity and the ability to perceive a wider range of colors compared to other mammals may have contributed to the enhanced color diversity in specific primate clades

62 (Bell et al., 2021). However, the evidence for coevolution of hair coloration, specifically red hair and color vision in primates, remains mixed (Fernandez and Morris, 2007; Kamilar et al., 2013).

64 Our understanding of primate hair color may benefit from broader sampling across wild populations and/or analyses conducted on smaller phylogenetic scales. macro-scale studies. Across primates, the primary trend is that hair density decreases as body size increases (Schwartz and Rosenblum, 1981; Sandel, 2013). One early hypothesis argued that 
glands, sweat production, and a change to a dry savannah environment — may have aided thermoregulation (i.e., "body-cooling hypothesis") (Post et al., 1975; Wheeler, 1992; Jablonski

72 and Chaplin, 2000). Despite various physiological models testing evidence of the body-cooling

73 hypothesis (Schwartz and Rosenblum, 1981; Wheeler, 1992; Chaplin, George, Jablonski, Nina

74 G., Cable, 1994), there is only rare empirical evidence for this phenomenon within primates

75 (Best et al., 2019). There also remains a poor understanding of how hair density in primates may be impacted by other factors, such as climate. Because hair does not preserve in the fossil record,

77 studies on wild primates can provide critical insights into the evolutionary mechanisms underlying one of the most interesting traits among humans.

This study examined whole-body pelage color and hair/follicle density across Indriidae-

80 a diverse clade of lemurs. Since the Indriidae clade varies in critical aspects known to drive

81 primate (including human) hair variation, they make a good proxy for testing multiple hair

82 hypotheses that have not yet been jointly assessed in one study. Our overarching goals were to 1)

83 examine if Indriidae pelage variation varies across distinct phylogenetic scales and 2) determine

84 if multiple, non-exclusive selective pressures can impact the same trait. Specifically, we aimed to

85 jointly assess the impacts of climate, body size, and color vision on hair evolution at distinct

86 phylogenetic scales. Collectively, this family (comprising three genera: nocturnal Avahi and

87 diurnal Indri and Propithecus) inhabits almost every bio-climate of Madagascar (e.g., humid

88 rainforest, temperate forests, open spiny forest, mangroves) (Mittermeier, Russell A. et al.,

89 2010). The hair of the 13 species in our study varies intra- and interspecifically in both color

90 (e.g., melanic, tricolored orange) and growth morphologies (e.g., long silky hairs, short hairs)

91 (Petter and Peyrieras, 1972; Tattersall, 1986; Mittermeier, Russell A. et al., 2010; King et al.,

92 2014; Rakotonirina et al., 2014). Indriidae also vary in body size ( $\approx 1 \mathrm{~km}($ Avahi $), \approx 3-8 \mathrm{~km}$ 
93 (Propithecus), $\approx 10 \mathrm{~km}($ Indri)) — and phylogenetic relatedness likely impacts body size evolution

94 (Lehman, 2007). Thus, we specifically (1a\2a) aimed to uncover how climate and body size

95 influences: pelage brightness (i.e., black color), hue (i.e., red color), and hair follicle density

96 across Indriidae and within Propithecus. We expected that climate impacts pelage color and

97 density evolution distinctly across different phylogenetic scales. We predicted that body size

98 only impacts hair/follicle density, based on evidence from other primates (Sandel, 2013). Diurnal

99 Indriidae (Indri and Propithecus) also vary in their color vision. In many species, some females

100 have trichromatic color vision (ability to distinguish reddish and greenish hues), while males and

101 other females are red-green color blind (polymorphic color vision; Jacobs et al., 2017). Although

102 this feature occurs in some other day-active lemurs, Indriidae has been found to exhibit greater

103 genetic variation in color vision across species (Jacobs et al., 2017). Accordingly, we (2b) aimed

104 to understand how this variation in color vision impacts pelage hue in diurnal genera. We

105 predicted that populations with enhanced capacity for trichromatic color vision would have

106 individuals with redder pelage (Sumner and Mollon, 2003). Our results provide critical insight

107 into how multiple variables impact primate hair evolution across scales. Importantly, this family

108 consists solely of vertical clingers and leapers, which means they exhibit upright locomotory

109 posture similar to humans (via bipedal hopping (Schmidt, 2011)). Thus, these results

110 (specifically those on hair density) may provide insight into human hair evolution.

112 Methods

113 Hair morphology and body size data collection

114 We used hair color and density measurements from museum research skins $\left(\mathrm{N}_{\text {Total }}=63\right.$;

$\left.115 \mathrm{~N}_{\text {Museum }}=59\right)$ and living animals in one wild population $\left(\mathrm{N}_{\text {Wild }}=4, P\right.$. diadema from 
Tsinjoarivo) (SI 1). Museum samples spanned three museum collections (SI 2). In total, we sampled six Avahi populations (Figure 1A), 23 Propithecus populations (Figure 1B), and four Indri populations (Figure 1C). Our sampling included nocturnal and diurnal genera (Figure 1D) across all significant bioclimatic regions in Madagascar (Figure 1E). Many individuals did not have available age or sex-class data. Hence, we did not test for differences between age classes or sex. Although some preliminary evidence suggests there may be subtle pelage dichromatism, sifakas are unlikely highly sexually dichromatic in terms of coloration. Instead, sifakas exhibit more significant visible variation within sexes (i.e., bimorphism in males) (Lewis \& Van Schaik, 2007; Mittermeier et al., 2010; Spriggs, 2017; Tapanes et al., 2018). Measurements of hair from wild sifakas consisted of following the same protocol as museum individuals. We also extracted body length (mm), measured from head to tip of tail, from all individuals as a proxy for body size using Photoshop CC 6. We standardized all measurements using the known length of a ruler in the photos. Wild sifakas were captured for ongoing parallel research using a standard capture protocol established by the Prosimian Biomedical Survey Project (PBSP) Team (used on 750+ lemurs, 16+ sites, and 35+ species since 2000) (Dutton et al., 2003; Irwin et al., 2010). Groups were habituated before capture. The capture team was led by a trained professional, and captures were performed at close range using Pneu-dart $9 \mathrm{~mm}$ disposable non-barbed darts containing tiletamine/zolazepam (Telazol) for immobilization.

\section{[Figure 1 Here]}

\section{$\underline{\text { Hair coloration collection }}$}

We used color-calibrated photographs of all animals $(\mathrm{N}=63$ individuals; SI 1) and a 
140 We calibrated each image against a color standard with 24 color squares of known reflectance

141 values. The camera color mode was set to 'faithful.' The camera was calibrated with a grey

142 standard to set a manual white balance. All individuals were photographed against dull

143 backgrounds using the adjacent method (Bergman and Beehner, 2008; Kendal et al., 2013). We

144 followed established protocols for calibrating photos in previous studies for both museum and

145 wild specimens (Stevens et al., 2007; 2009).

We used the Red-Green-Blue (RGB) color model and extracted all RGB values using

147 Photoshop CC 6 across 14 body regions. Due to the high degree of variation across the pelage of

148 the Propithecus tail, ventral surface, and dorsal surface, we divided measurements of these

149 regions into three quadrants (lower, mid, and upper) (SI 3). If one of these regions was damaged,

150 we took measurements from the center as the "average." Primate hair occupies a relatively small

151 color space, primarily varying along two axes. The first relates to variation in luminance and

152 exhibits little chromatic variation and is captured by similar red, green, and blue values. Thus,

153 we used RGB averages here as a proxy for 'brightness' in a hair patch to indicate if the hair is

154 white, a shade of grey, or black. The second axis of variation is hue and indicates variation along

$155 \mathrm{a} \mathrm{red} / \mathrm{brown}$ axis and can be captured by a ratio of red to green. The latter is because the green

156 and blue channels are most similar, while the red channel exhibits higher values on average. As

157 the Red-Green ratio increases, hair appears increasingly red (Kamilar et al., 2013). We ran a

158 correlation matrix across color values and removed any that were highly correlated with each

159 other $(\mathrm{r}>.90)$. This reduced our hair color variables to RGB averages and RG ratios for the (1)

160 crown, (2) cheek, (3) dorsal torso, (4) ventral torso, (5) forelimb, (6) hindlimb, and (7) tail. In

161 total, we collected 882 brightness and 882 hue measurements (63 individuals x 14 sampling

162 regions). Previous work on museum skins indicated no effect of storage time on pelage 
coloration from 142 museum skins collected over 100 years (1898 and 1998) (Kamilar et al., 2013).

\section{$\underline{\text { Hair and follicle density collection }}$}

We used a protocol that borrows from dermatological methods and instrumentation, which automates hair density measurements (Avram and Rogers, 2009). We used CompareViewHair® software (STR Technologies) tools combined with a specialized hand-held digital light microscope (ProScope HR2@; Bodelin) with a 100x lens. The software included a built-in procedure for calibrating the lens and software before use. The hair of an animal was parted, and the lens was placed on the skin. A light within the microscope illuminated the skin and provided needed light for subsequently photographing the area. We collected microscopy images (detailing transects of hair follicles and shafts) and compiled semi-automated measurements in the laboratory using this system. We examined two hair morphology properties: hair density (shafts $/ \mathrm{cm}^{2}$ ) and follicle density (infundibula $/ \mathrm{cm}^{2}$ ).

We collected three microscopy photos (replicates) from five body regions (SI 4) of each animal ( $\mathrm{n}=47$ individuals) (SI 1) using the hand-held microscope, adhering to a previously established protocol (Bradley et al., 2014). The method provided a visual transect/plot of follicles (i.e., infundibula) and the number of hair shafts emerging from each. We used the 'density tool' in CompareViewHair® software to estimate the number of infundibula per $\mathrm{cm}^{2}$ (i.e., follicle density). We marked each follicle strand manually and used that number to estimate the final value in any given region (given the specific magnification). However, this protocol assumed that the entire photograph was visible, which was not always the case. Therefore, in our final measurements for 'follicle density,' we used the value the software provided of density per $\mathrm{cm}^{2}$ and divided it by the visible photo's proportion. Similarly, for our final measurement for 'hair 
187 density,' we used the value the software calculated for density per $\mathrm{cm}^{2}$ and multiplied it by the

188 average number of hairs emerging from each follicle. In total, we collected 235 hair and 235

189 follicle density measurements (47 individuals x 5 body regions). Previous work on museum skins

190 shows no effect of storage time on pelage density for skins collected over 100 years (Bradley et

191 al., 2014).

192

Climatic and phylogenetic data collection

We collected climate and environmental data from 33 sampling locations across

195

196

197

198

199

200

201

202

203

204

205

206

207

208

209
Madagascar (Figure 1). Specifically, we extracted data from WorldClim (version 1) that

consisted of averages from 1960 to 1990 . This likely created some noise in the data given

museum data spanned the early 1900s to late 1990s. However, sifaka generation times are long

( $\sim 20$ years $)$ - thus, the data are likely representative of accurate averages across bioclimates and

phenotypes. Localities were obtained from museum records, and we used Google Earth to obtain geographic coordinates of the nearest forested area in the species range. Localities were listed as

forests or towns with directional coordinates (e.g., $40 \mathrm{~km} \mathrm{~W}$ of Tamatave). We used R packages

'raster' and 'sp' to extract all localities' climate data in the WorldClim database (Pebesma and

Bavand, n.d.; Hijmans and Etten, 2012). We ran a correlation matrix for all 19 bioclimatic

variables and removed any highly correlated variables $(r>.80)$. In the end, we used five

bioclimatic variables in our comparative analysis as predictor variables (SI 5).

\section{DNA extractions for opsin genotypes}

We categorized diurnal Indriidae color vision status (e.g., polymorphic color vision, dichromatic - red-green colorblind) based on X-linked opsin genotypes (Jacobs et al., 2017, 
2019). Our analysis included diurnal Indriidae represented by a subset of species/populations for which pelage data were also available $\left(N_{\text {species }}=7 ; N_{\text {populations }}=10 ;\right.$ SI 6). Opsin genotypes for populations of diademed sifaka (Propithecus diadema), Milne-Edwards's sifaka (Propithecus edwardsi), golden crowned sifaka (Propithecus tattersalli), Verreaux's sifaka (Propithecus verreauxi), and Indri indri were previously published (Jacobs et al., 2017). Data for the silky sifaka (Propithecus candidus) and Perrier's sifaka (Propithecus perrieri) were based on opsin genotypes obtained from five individuals from Anjanaharibe-Sud $\left(\mathrm{N}_{\mathrm{X} \text { chromosomes }}=8\right)$ and Analamera $\left(\mathrm{N}_{\mathrm{X} \text { chromosomes }}=8\right)$ populations, respectively, following (Jacobs et al., 2019). Briefly, we extracted genomic DNA from blood/tissue samples using phenol-chloroform-isoamyl extraction protocols (Sambrook et al., 1989). We used quantitative PCR (Mic qPCR Cycler, Bio Molecular Systems; Rotor-Gene Q, Qiagen) to amplify exons 3 and 5 of the X-linked opsin gene. Amplification was followed by high-resolution melt analysis (HRMA) (following (Jacobs et al., 2016)), and we determined genotypes for each exon based on the observed melt curve shape and temperature compared to positive controls $\left(\mathrm{N}_{\text {Replicates }}=2\right.$ per exon). To further confirm genotype calls, we Sanger sequenced qPCR amplicons from at least two individuals representing each observed melt curve. All sequences matched scored genotypes based on melt curves.

We estimated the peak spectral sensitivity of observed opsin alleles in each population (following (Jacobs et al., 2017)) and determined the difference between the two alleles with maximum and minimum peak spectral sensitivities. These values, along with a total number of observed alleles, were used in downstream analyses as proxies for enhanced trichromatic color vision. Trichromatic color vision is most optimal with more widely separated photopigments (e.g., (Osorio et al., 2004)). A greater number of opsin alleles results in an increased proportion of trichromatic individuals in a population. 
234 Analyses

235

236 Climate and body size effects on pelage brightness and hue

247 Markov chain Monte Carlo algorithms (MCMC) via the 'MCMCglmm' package in R (Hadfield,

252 of climate variables on bumblebee body size (Ramírez-Delgado et al., 2016) and frog vocal

253 signals (McLean et al., 2013). Each model included one color (or hair density) PC value as the

254 dependent variable and the bioclimatic variables (SI 5) and body size as independent variables,

255 with species and phylogeny considered random factors. We log-transformed PC values, 
bioclimatic variables, and body size to achieve normality. All models ran for 5,000,000 iterations after a burn-in of 500,000 iterations and a thinning interval of 500 using flat priors. We assured effective sampling sizes were adequate for all our models (i.e., ESS virtually equal to MCMC sample size) (Villemereuil and Nakagawa, 2014).

We assigned statistical significance when $\mathrm{pMCMC} \leq 0.05$ (which is equivalent to a $\mathrm{p}$ value (Villemereuil and Nakagawa, 2014)) and when the confidence interval for a given variable did not include zero (Ramírez-Delgado et al., 2016). To estimate what fraction of the pelage variation was attributable to phylogenetic relatedness, we calculated $H^{2}$ from Lynch (Lynch, 1991) (equivalent to Pagels's $\lambda$ ) which corresponds to the degree of variation in a given trait attributable to phylogenetic relatedness (Hansen and Orzack, 2005; Kamilar and Cooper, 2013). We ran the models across the whole Indriidae family and within the Propithecus genus. Using G*Power analysis (Faul et al., 2009), we estimated the PGLMMs would detect a small effect ((Indriidae, 0.25)-(Propithecus, 0.35)) with $\approx 80 \%$ power.

\section{Climate and body size effects on pelage density}

We conducted two principal component analyses (PCA) of hair and follicle density values: one across all Indriidae taxa and a second within the Propithecus genus. We removed any variables whose vectors strongly correlated in each of the PCAs. We used the resulting PC values with eigenvalues over one as dependent variables in our PGLMM models, following the methodology outlined above (see: climate and body size effects on pelage brightness and hue). Using G*Power analysis (Faul et al., 2009), we estimated the Indriidae PGLMM would detect a small effect (0.35), and the Propithecus PGLMM would detect a moderate effect (0.50) with $\approx 80 \%$ power. We also conducted an Analysis of Variance (ANOVA) to test for differences 
279 between hair or follicle density across distinct body parts.

$\underline{\text { Polymorphic trichromacy and pelage hue variation }}$

We ran one PCA on hue variables among a subset of individuals from which we had paired opsin genotypes and pelage measurements from the same population. We used any PCs

284 with eigenvalues over one as the dependent variable in our linear models. To estimate the relationship between pelage hue and color vision, we conducted both (1) a simple linear regression and (2) PGLMM. Due to the small sample size ( $\mathrm{n}=10$ localities/populations) (SI 6), we assumed that the "true" result likely fell between a model where lambda $=0$ (simple linear model) and one where lambda = 1 (PGLMM). We followed the methods described previously, except we used 'spectral sensitivity range' (i.e., difference in opsin spectral sensitivity) and the 'total number of opsin alleles' as our independent variables. Despite the low sample size, using G*Power analysis (Faul et al., 2009), we estimated the simple linear model would detect a moderate effect $(0.65)$ with $\approx 80 \%$ power.

\section{Results}

Climate and body size effects on pelage brightness and hue 
302 precipitation seasonality (i.e., higher rainfall, more humid) (Figure 2A). Brightness across

303 Indriidae exhibited a moderate phylogenetic signal (0.68) (Table 1). On the hue PCA, the first

304 two PCs explained $\approx 53 \%$ of the variation (SI 9, SI 10). The highest loadings were hindlimb,

305 crown and cheek hue (PC1), as well as cheek and dorsal torso hue (PC2) (SI 10). We found a

306 statistically significant relationship between PC2 and temperature annual range (Table 2).

307 Indriidae with redder pelage hues live in regions that experience large ranges in temperature (i.e.,

308 lower temperatures) (Figure 3, SI 24). Hue values across Indriidae exhibited moderate

309 phylogenetic signal (0.53-0.67) (Table 2).

310

311 [Table 1 Here]

312 [Table 2 Here]

313 [Figure 2 Here]

314 [Figure 3 Here]

$\underline{\text { Within Propithecus }}$

For the brightness PCA, the first PC explained $\approx 70 \%$ of the variation within Propithecus

318 (SI 11). The highest loadings on PC1 were hindlimb, dorsal torso, and forelimb brightness (SI

319 12). We found a statistically significant and positive association between hair brightness and

320 mean annual temperature (Table 1). Thus, darker pelage within Propithecus is associated with

321 colder forests (Figure 2B). Brightness across Indriidae exhibited a high phylogenetic signal

$322(0.90)$ (Table 1). For the hue PCA, the first three PCs explained $\approx 80 \%$ of the variation within

323 Propithecus (SI 13, SI 14). The highest loadings were forelimb, dorsal torso, and hindlimb hue

324 (PC1), cheek, ventral torso, and hindlimb hue (PC2), and crown hue (PC3) (SI 14). We found a 
325 statistically significant relationship between PC2 and mean annual temperature, precipitation seasonality, precipitation of the wettest month, and body size (Table 3). Thus, redder hues within Propithecus are associated with lower precipitation seasonality (and higher rainfall). We found no statistically significant relationships between either PC1 or PC3 with the tested variables. There was low to moderate phylogenetic signal for hair hue within Propithecus (0.22-0.63) (Table 3).

[Table 3 Here]

Across Indriidae highest loadings were forelimb, hindlimb, and crown follicle density (PC1), ventral torso hair density and crown and hindlimb follicle density (PC2), and dorsal torso hair density (PC3) (SI 16). We found a statistically significant relationship between $\mathrm{PC} 1$ and precipitation seasonality as well as between PC3 and body size (Table 4). Specifically, the results suggest that in forests with high precipitation seasonality (dryer, open forests exposed to the sun) individuals exhibit an

342 increase of follicle density on the limbs and crown (Figure 4). Also, smaller taxa have the highest

343 hair density; and, larger individuals exhibit lower hair density on average (Figure 5). Pelage

344 density across Indriidae exhibited low phylogenetic signal (0.21-0.33) (Table 4). We also found a 345 statistically significant difference between hair density across body regions sampled (Table 5).

346 Specifically, we found the crown and forelimbs exhibit the greatest hair density, and the ventral 
348 follicle density of regions sampled (Table 5, Figure 6B).

349

350 [Table 4 Here]

$351 \quad$ [Table 5 Here]

352 [Figure 4 Here]

353 [Figure 5 Here]

354 [Figure 6 Here]

355

356

357

358

359

360

361

362

363

364

365

366

367

368

369

370

[Table 6 Here]

\section{Within Propithecus}

Within Propithecus, the first three PCs explained $\approx 70 \%$ of the variation (SI 17 , SI 18).

The highest loadings were forelimb follicle density, crown hair density, and hindlimb follicle density (PC1), crown and hindlimb follicle density as well as hindlimb hair density (PC2), and ventral torso hair density (PC3) (SI 18). We found no statistically significant relationships between any PC value and either climate or body size variable (Table 6). Similarly to Indriidae, we detected significant differences between hair density and distinct body regions (SI 19), and no differences were detected among follicle density within Propithecus (SI 19, SI 20).

\section{Polymorphic trichromacy and pelage hue variation}

For the hue PCA using only a subset of the data from Indri and Propithecus, the first two PCs explained $\approx 66 \%$ of the variation (SI 21 ). The highest loadings to PC1 were forelimb, dorsal torso, and hindlimb hue, and the highest loadings to PC2 were cheek, ventral torso, and hindlimb

371 hue (SI 22). From the simple linear model (lambda $=0$ ), we found a statistically significant 
372 relationship between PC1 with the difference in opsin spectral sensitivity $\left(\mathrm{p}=0.03 ; \mathrm{R}^{2}=.51\right)$,

373 but not with the overall number of alleles in the population (Table 7). Specifically, we found a

374 significant negative linear relationship between spectral sensitivity and hue (Figure 7). Despite

375 the smaller sample size of the PGLMM (lambda =1), we detected a similar association that

376 approaches statistical significance $(\mathrm{pMCMC}=0.09)$ and only moderate phylogenetic signal

377 (0.41) (SI 23).

378

$379 \quad[$ Table 7 Here]

$380 \quad$ [Figure 7 Here]

\section{Discussion}

Our overarching goals were to examine 1) if Indriidae pelage traits varied across distinct

phylogenetic scales and 2) if multiple non-exclusive selective pressures would impact the same sifakas (genus Propithecus) vary with climate, body size, and/or color vision.

387

388

\section{Climate and body size effects on pelage brightness and hue}

Our first sub-aim sought to uncover how climate and body size influenced pelage brightness and hue across two distinct scales (across a family [Indriidae] and within a genus [Propithecus]). Our results show distinct trends across scales regarding dark pelage (i.e., brightness). Specifically, across Indriidae, greater brightness is associated with greater precipitation seasonality (Table 1). Greater hue, in contrast, is associated with greater ranges in annual temperature across Indriidae (lower overall temperatures (SI 24)) (Table 2). Thus, black

coats occur in regions of lower precipitation seasonality, and redder coats in areas that 
experience larger ranges in temperature (Figure 2A, Figure 3). Generally, in Madagascar, low precipitation seasonality is strongly and negatively associated with high precipitation forests of the East (SI 24). The result for brightness in Indriidae follows Gloger's rule, predicting an increase in eumelanin (i.e., black pigments) (Delhey, 2017). Yet, within Propithecus, results indicate a relationship between brightness and mean annual temperature (Table 1). Thus, darkhaired sifakas are generally associated with colder regions, which serves as evidence of Bogert's rule (or the thermal melanism hypothesis) (Figure 2B) (Bogert, 1949).

Recent work highlights that discovering evidence for Bogert's or Gloger's rule may merely reflect differences in geographic space, scale, and climate gradients (Delhey et al., 2019). We show in this analysis that different effects can be detected across the primate coat, depending on the sampling scale. Additionally, the strength of selective pressures acting on pelage may also play a role in detecting either rule. For example, if the need to camouflage or avoid parasites is high, rainfall (which predicts Gloger's rule) may strongly affect pelage color (da Silva et al., 2016). This is because higher rainfall may also be associated with higher loads of parasites (Shearer and Ezenwa, 2020) or may indicate low light forested environments that enhance crypsis for dark animals (Caro, 2005; Delhey, 2018). In contrast, if the need for thermoregulation is high, temperature (which predicts Bogert's rule) may have a more substantial effect on pelage color than rainfall (Galván et al., 2018). It is hypothesized that black colors aid with thermoregulation in colder climates since they likely increase absorption of ultraviolet rays. While this has been documented widely in ectoderms and recently in birds (Bogert, 1949; Clusella Trullas et al., 2007; Bishop et al., 2016; Xing et al., 2016; Delhey et al., 2019), to date, our results serve as the first empirical evidence for Bogert's rule in mammals. 
419 size only influenced hair hue across the Propithecus clade and otherwise did not affect our

420 coloration models across either scale (Table 2, Table 3). At first glance, smaller individuals seem

421 to exhibit redder hues; however, this trend is driven mostly by Propithecus species on the

422 western side of the island. This may indicate subtler variation between species that our analysis

423 does not capture. However, these results may also reflect broader climatic trends, variations in

424 color vision (addressed below), or is perhaps the product of our body size sampling

425 methodology. Second, most of the coloration traits we sampled exhibited low to moderate

426 phylogenetic signals. Our brightness models, on the other hand, had a high phylogenetic signal

$427(\approx 0.80)$. Thus, brightness may implicate genetic drift (Losos, 2008; Revell et al., 2008).

428 However, it is well established that primate coat color exhibits little to no phylogenetic signal

429 and is a poor marker of phylogeny (Bell et al., 2021). An alternative explanation for such a high

430 signal is that it is an "artificial" result from taxonomic inflation that merely reflects patterns of

431 geographic variation (Kamilar and Muldoon, 2010).

432

Climate and body size effects on pelage density

Our second sub-aim sought to uncover how climate and body size influenced pelage hair

435 and follicle density across two distinct scales (across a family [Indriidae] and within a genus

436 [Propithecus]). We predicted that body size would affect density because these variables are

437 associated across primates. Body size may also have been one of the factors influencing the

438 reduction of the hairy coat in hominins (Schwartz and Rosenblum, 1981; Sandel, 2013). We

439 found support for this prediction across Indriidae (Table 4). Specifically, higher hair density is

440 associated with smaller body sizes (Avahi), and lower hair density is found in larger animals

441 across Indriidae (Figure 4). One explanation for this result may be that interfollicular distance 
442

443

444

445

446

447

448

449

450

451

452

453

454

455

456

457

458

459

460

461

462

463

464

increases as surface area increases, thus, decreasing hair density in larger animals (Sandel, 2013).

In addition, this relationship may provide thermoregulatory benefits since larger animals may

struggle more to dissipate heat (Schwartz and Rosenblum, 1981). Our models show that climate

also influences pelage variation across Indriidae. Limb and crown follicle density increases as

precipitation seasonality increases (i.e., shifting to dry open habitats) (Table 4; Figure 4).

Interestingly, the crown and forelimbs are also the regions that exhibit the highest degree of hair density (Figure 6A) — but not follicle density (Figure 6B). Thus, there are likely two mechanisms

to increase density: (1) increase hair follicle density or (2) increase the number of hairs emerging from each follicle. Since follicle density is determined in early embryogenesis, follicle density may be more strongly genetically determined than hair density (which may be more plastic to rapid environmental changes, such as seasonality) (Tapanes et al., 2021). Alternatively, follicle density may be easier to measure without error and could be a more reliable estimate for 'hairiness.'

Nevertheless, the shift towards drier habitats exposed to more sun (such as Western spiny thickets) leads to an increase in follicle density in the limbs and crown (Figure 4), where hair density is already the highest of all regions (Figure 6A). Since all Indriidae are vertical clingers and leapers, the crown and upper limbs are the most directly impacted by the sun's rays — as they are known to hold up their arms while jumping bipedally. Thus, increased hair density in these regions may aid individuals in this clade with protection from ultraviolet rays (and/or protect the underlying skin from abrasion in spiny thickets). We consider this density pattern may help prevent photolysis of folate, an essential metabolite in the formation of the embryonic neural tube. Protection against folate leaching was likely a selection target in the evolution of high melanization within the skin of humans living in high UV areas (Jablonski and Chaplin, 2000). 
465 In humans, lower levels of folate (or folate deficiency) are also often significantly associated with hair loss (Ertug, 2018; Almohanna et al., 2019), and folate may play a significant role within the hair follicle (Durusoy et al., 2009). Since the skin of most Indriidae is already highly melanized, it is not surprising that populations exposed to hotter environments and more direct

472 early mechanism to prevent folate leaching from key body regions exposed to direct UV rays.

473 This body hair pattern potentially preceded the evolution of "naked" skin and sweat glands. 1992) argued that bipedal hominins evolved naked skin to allow for evaporative cooling.

477 However, Wheeler $(1985,1992)$ also argued as part of this hypothesis that bipedal hominins

478 likely retained hair on the crown and shoulders to protect those areas from UV exposure.

479 Indriidae, presenting similar postural locomotion to humans, exhibit follicle density increases in their body regions most exposed to potential UV damage. Indriidae present a unique opportunity thermoregulation across and within populations to clarify potential mechanisms driving this pattern of hair variation in upright primates. 
either body size or climate. This may be due to a smaller sample size available for Propithecus density which we estimated would not pick up small effects $\left(\mathrm{G}^{*}\right.$ power analyses detailed in methods). Alternatively, at smaller phylogenetic scales, other aspects of hair morphology that we did not measure (e.g., overall shape, length, thickness) may directly relate to either climate or body size best. For example, there are no differences in hair density between chimpanzees and humans, but there are significant differences in gland density, sweat production, and overall hair morphology (Kamberov et al., 2018). Hair and follicle density was likely one of a few aspects of hair evolution that were potentially malleable and allowed rapid adaptation to changing climatic environments for hominins. More research is needed across non-human and human primate hair to understand why and how humans retained hair in the places they did (e.g., scalp, pubic) — a critical part of the story in the evolution of our apparent "nakedness."

\section{Polymorphic trichromacy and pelage hue variation}

Our third sub-aim sought to understand the relationship between color vision and pelage hue in diurnal genera. We found support for our prediction that populations with enhanced capacity for trichromatic color vision would also contain individuals with redder pelage (as hypothesized in (Sumner and Mollon, 2003)). Many primates are unique among placental mammals in having trichromatic color vision, a feature that is thought to be advantageous for foraging on "red" foods (i.e., ripe fruit, young leaves), detecting predators, and/or tracking conspecifics (Kawamura et al., 2012; Surridge et al., 2003). Indeed, reddish skin coloration observed in many primate species is thought to play a salient role in conspecific signaling for primates (Moreira et al., 2019). However, previous support for the coevolution of red hair and trichromacy in primates is mixed (Fernandez and Morris, 2007; Kamilar et al., 2013). Our results 
511 indicate a significant positive relationship between hue ('redness') and measures of enhanced

512 trichromacy in Indriidae (Table 7). The similarity in results between both models (lambda=0 vs.

513 lambda=1) indicates a likely significant relationship between hue and opsin genotype variation in

514 diurnal Indriidae. Specifically, red hues are more likely to occur when there is a more significant

515 difference spectral sensitivity between opsin alleles (Figure 7), suggesting increased

516 discriminability of such hues. Results across Indriidae, which exhibits more subtle inter- and

517 intra-species variation in trichromacy than has been previously considered, suggests that there

518 may be a more complex and nuanced coevolutionary relationship between red hair coloration in

519 primates and trichromatic color vision that deserves further attention (Table 7).

\section{Conclusions}

Climate, body size, and color vision all impact hair variation across Indriidae, but the

523 extent that each exerts its influence on the phenotype varies by sampled phylogenetic scale.

524 These results have considerable implications for our understanding of primate (including human)

525 hair evolution because it suggests that larger macro-scale trends detected across primates may

526 not sufficiently explain variation within a genus, species, or population. Understanding wild non-

527 human primate hair can also potentially help shed light on the evolution of hominin hair. Further

528 work on primate hair should sample across smaller geographic or phylogenetic scales and from

529 diverse non-human and human populations. 


\section{Acknowledgments}

532

533

534

535

536

537

538

539

540

541

542

543

544

545

546

547

548

549

550

1

42

We thank the American Museum of Natural History, the Smithsonian National Museum of Natural History, and Harvard University's Museum of Comparative Zoology. Special thanks to museum staff that helped with Propithecus collections, including Ian Tattersall, Darrin Lunde, Mark Omura, Eleanor Hoeger, and Marisa Surovy. We also thank the Government of Madagascar (Ministry of the Environment and Sustainable Development), SADABE, Madagascar Biodiversity Partnership (MBP), Omaha Zoo, the University of Antananarivo, and Anthropobiologie et Développement for facilitation and partnership. 


\section{References}

Allen, W.L., Higham, J.P., 2013. Analyzing visual signals as visual scenes. American journal of primatology. $75,664-82$.

Almohanna, H.M., Ahmed, A.A., Tsatalis, J.P., Tosti, A., 2019. The Role of Vitamins and Minerals in Hair Loss : 51-70.

Avram, M.R., Rogers, N.E., 2009. The use of low-level light for hair growth: Part i. Journal of Cosmetic and Laser Therapy. 11, 110-117.

Barrett, R.D.H., Laurent, S., Mallarino, R., Pfeifer, S.P., Xu, C.C.Y., Foll, M., Wakamatsu, K., Duke-Cohan, J.S., Jensen, J.D., Hoekstra, H.E., 2019. Linking a mutation to survival in wild mice. Science. 363, 499-504.

Bell, R.B., Bradley, B.J., Kamilar, J.M., 2021. The Evolutionary Ecology of Primate Hair Coloration : A Phylogenetic Approach.

Bergman, T.J., Beehner, J.C., 2008. A simple method for measuring colour in wild animals: validation and use on chest patch colour in geladas (Theropithecus gelada). Biological Journal of the Linnean Society. 94, 231-240.

Best, A., Lieberman, D., Kamilar, J., 2019. Diversity and evolution of human eccrine sweat gland density. Journal of Thermal Biology. 84, 331-338.

Bishop, T.R., Robertson, M.P., Gibb, H., van Rensburg, B.J., Braschler, B., Chown, S.L., Foord, S.H., Munyai, T.C., Okey, I., Tshivhandekano, P.G., Werenkraut, V., Parr, C.L., 2016. Ant assemblages have darker and larger members in cold environments. Global Ecology and Biogeography. 25, 1489-1499.

Bogert, C.M., 1949. Thermoregulation in reptiles, a factor in evolution. Evolution. 3, 195-211.

Bradley, B.J., Walsh, S., Nishimura, A., Karlsson, J., Kamilar, J.M., 2014. The evolution of 
primate pelage: Morphological analysis of museum research skins. In: Program of the 83rd Annual Meeting of the American Association of Physical Anthropologists.

Caro, T., 2005. The adaptive significance of coloration in mammals. BioScience. 55, 125.

Chaplin, George, Jablonski, Nina G., Cable, T.N., 1994. Physiology, thermoregulation and bipedalism. Journal of Human Evolution. 27, 497-510.

Clusella Trullas, S., van Wyk, J.H., Spotila, J.R., 2007. Thermal melanism in ectotherms. Journal of Thermal Biology. 32, 235-245.

Cuthill, I.C., Allen, W.L., Arbuckle, K., Caspers, B., Chaplin, G., Hauber, M.E., Hill, G.E., Jablonski, N.G., Jiggins, C.D., Kelber, A., Mappes, J., Marshall, J., Merrill, R., Osorio, D., Prum, R., Roberts, N.W., Roulin, A., Rowland, H.M., Sherratt, T.N., Skelhorn, J., Speed, M.P., Stevens, M., Stoddard, M.C., Stuart-Fox, D., Talas, L., Tibbetts, E., Caro, T., 2017. The biology of color. Science. 357.

da Silva, L.G., de Oliveira, T.G., Kasper, C.B., Cherem, J.J., Moraes, E.A., Paviolo, A., Eizirik, E., 2016. Biogeography of polymorphic phenotypes: Mapping and ecological modelling of coat colour variants in an elusive Neotropical cat, the jaguarundi (Puma yagouaroundi). Journal of Zoology. 299, 295-303.

Delhey, K., 2017. Gloger's rule. Current Biology. 27, R689-R691.

Delhey, K., 2018. Darker where cold and wet: Australian birds follow their own version of Gloger's rule. Ecography. 41, 673-683.

Delhey, K., Dale, J., Valcu, M., Kempenaers, B., 2019. Reconciling ecogeographical rules: rainfall and temperature predict global colour variation in the largest bird radiation. Ecology Letters. 22, 726-736.

Durusoy, C., Ozenli, Y., Adiguzel, A., Budakoglu, I.Y., Tugal, O., Arikan, S., Uslu, A., 2009. 
The role of psychological factors and serum zinc, folate and vitamin B 12 levels in the aetiology of trichodynia : a case - control study. 789-792.

Dutton, A., Christopher, J., Randall, E., 2003. Biomedical Evaluation of Free-Ranging RingTailed Lemurs (Lemur Catta) in Tsimanampetsotsa Strict Nature Reserve, Madagascar. Journal of Zoo and Wildlife Medicine. 34, 16-24.

Ertug, E.Y., 2018. Research Article Reduced ferritin, folate, and vitamin B12 levels in female patients diagnosed with telogen effluvium. 1, 0-2.

Faul, F., Erdfelder, E., Buchner, A., Lang, A.G., 2009. Statistical power analyses using G*Power 3.1: Tests for correlation and regression analyses. Behavior Research Methods. 41, 11491160.

Fernandez, A.A., Morris, M.R., 2007. Sexual selection and trichromatic color vision in primates: Statistical support for the preexisting-bias hypothesis. American Naturalist. 170, 10-20.

Fratto, M.A., Davis, A.K., 2011. Do black-furred animals compensate for high solar absorption with smaller hairs? A test with a polymorphic squirrel species. Current Zoology. 57, 731736.

Galván, I., Rodríguez-Martínez, S., Carrascal, L.M., 2018. Dark pigmentation limits thermal niche position in birds. Functional Ecology. 32, 1531-1540.

Hadfield, J.D., 2010. MCMC methods for multi-response generalized linear mixed models: The MCMCglmm R package. Journal of Statistical Software. 33, 1-22.

Hansen, T.F., Orzack, S.H., 2005. Assessing Current Adaptation and Phylogenetic Inertia As Explanations of Trait Evolution: the Need for Controlled Comparisons. Evolution. 59, 2063. Herrera, J.P., Dávalos, L.M., 2016. Phylogeny and Divergence Times of Lemurs Inferred with Recent and Ancient Fossils in the Tree. Systematic Biology. 65, 772-791. 
620

621

622

623

624

625

626

627

628

629

630

631

632

633

634

635

636

637

638

639

640

641

642

Hijmans, R.J., Etten, J. V., 2012. Raster: Geographic analysis and modeling with raster data. R package version $2.0-12$.

Hoekstra, H.E., Krenz, J.G., Nachman, M.W., 2005. Local adaptation in the rock pocket mouse (Chaetodipus intermedius): Natural selection and phylogenetic history of populations. Heredity. 94, 217-228.

Irwin, M.T., Junge, R.E., Raharison, J.L., Samonds, K.E., 2010. Variation in physiological health of diademed sifakas across intact and fragmented forest at Tsinjoarivo, eastern Madagascar. American Journal of Primatology. 72, 1013-1025.

Jablonski, N.G., Chaplin, G., 2000. The evolution of human skin coloration. Journal of Human Evolution. 39, 57-106.

Jacobs, R.L., MacFie, T.S., Spriggs, A.N., Baden, A.L., Morelli, T.L., Irwin, M.T., Lawler, R.R., Pastorini, J., Mayor, M., Lei, R., Culligan, R., Hawkins, M.T.R., Kappeler, P.M., Wright, P.C., Louis, E.E., Mundy, N.I., Bradley, B.J., 2017. Novel opsin gene variation in largebodied, diurnal lemurs. Biology Letters. 13, 1-6.

Jacobs, R.L., Spriggs, A.N., MacFie, T.S., Baden, A.L., Irwin, M.T., Wright, P.C., Louis, E.E., Lawler, R.R., Mundy, N.I., Bradley, B.J., 2016. Primate genotyping via high resolution melt analysis: rapid and reliable identification of color vision status in wild lemurs. Primates. 57, $541-547$.

Jacobs, R.L., Veilleux, C.C., Louis, E.E., Herrera, J.P., Hiramatsu, C., Frankel, D.C., Irwin, M.T., Melin, A.D., Bradley, B.J., 2019. Less is more: lemurs (Eulemur spp.) may benefit from loss of trichromatic vision. Behavioral Ecology and Sociobiology. 73.

Kamberov, Y.G., Guhan, S.M., DeMarchis, A., Jiang, J., Wright, S.S., Morgan, B.A., Sabeti, P.C., Tabin, C.J., Lieberman, D.E., 2018. Comparative evidence for the independent 
evolution of hair and sweat gland traits in primates. Journal of Human Evolution. 125, 99105.

Kamilar, J.M., Bradley, B.J., 2011. Interspecific variation in primate coat colour supports Gloger's rule. Journal of Biogeography. 38, 2270-2277.

Kamilar, J.M., Cooper, N., 2013. Phylogenetic signal in primate behaviour, ecology and life history. Philosophical transactions of the Royal Society of London. Series B, Biological sciences. $368,20120341$.

Kamilar, J.M., Heesy, C.P., Bradley, B.J., 2013. Did trichromatic color vision and red hair color coevolve in primates? American Journal of Primatology.

Kamilar, J.M., Muldoon, K.M., 2010. The climatic niche diversity of Malagasy primates: A phylogenetic perspective. PLoS ONE. 5.

Kawamura, S., Hiramatsu, C., Melin, A.D., Schaffner, C.M., Aureli, F., Fedigan, L.M., 2012. Polymorphic Color Vision in Primates: Evolutionary Considerations. 93-120.

Kendal, D., Hauser, C.E., Garrard, G.E., Jellinek, S., Giljohann, K.M., Moore, J.L., 2013. Quantifying Plant Colour and Colour Difference as Perceived by Humans Using Digital Images. PLoS ONE. 8, 1-11.

King, T., Rakotonirina, L.H.F., Rakotoarisoa, A.H., Razafindramanana, J., Ratsimbazafy, J., 2014. Distributional limits and melanism in the south-west of the range of the crowned sifaka (Propithecus coronatus), Madagascar. Primate Conservation. 28, 55-64.

Lasisi, T., Ito, S., Wakamatsu, K., Shaw, C.N., 2016. Quantifying variation in human scalp hair fiber shape and pigmentation. American Journal of Physical Anthropology. 160, 341-352.

Lehman, S.M., 2007. Ecological and phylogenetic correlates to body size in the Indriidae. 
Lewis, R.J., Van Schaik, C.P., 2007. Bimorphism in male verreaux’s sifaka in the Kirindy Forest of Madagascar. International Journal of Primatology. 28, 159-182.

Losos, J.B., 2008. Phylogenetic niche conservatism, phylogenetic signal and the relationship between phylogenetic relatedness and ecological similarity among species. Ecology Letters. $11,995-1003$.

Lynch, M., 1991. Methods for the analysis of comparative data in evolutionary biology. Evolution. 45, 1065-1080.

McLean, M.J., Bishop, P.J., Nakagawa, S., 2013. Assessing the Patterns of Evolution in Anuran Vocal Sexual Signals. Evolutionary Biology. 40, 141-149.

Mittermeier, Russell A., Louis, Jr., Edward E., Richardson, M., Schwitzer, C., Langrand, O., Rylands, Anthony B., Hawkins, Frank, Rajaobelina, S., Ratsimbazafy, J., Rasoloarison, R., Roos, C., Kappeler, P.M., MacKinnon, K.C., 2010. Lemurs of Madagascar, 3rd ed.

Moreira, L.A.A., Duytschaever, G., Higham, J.P., Melin, A.D., 2019. Platyrrhine color signals: New horizons to pursue. Evolutionary Anthropology. 28, 236-248.

Norton, H.L., Edwards, M., Krithika, S., Johnson, M., Werren, E.A., Parra, E.J., 2016. Quantitative assessment of skin, hair, and iris variation in a diverse sample of individuals and associated genetic variation. American Journal of Physical Anthropology. 160, 570581.

Osorio, D., Smith, A.C., Vorobyev, M., Buchanan-Smith, H.M., 2004. Detection of fruit and the selection of primate visual pigments for color vision. American Naturalist. 164, 696-708.

Paus, R., Foitzik, K., 2004. In search of the "hair cycle clock": A guided tour. Differentiation. $72,489-511$.

Pebesma, E.J., Bavand, R.S., n.d. Classes and methods for spatial data in R. R News. 5, 9-13. 
Petter, J.J., Peyrieras, A., 1972. Melanization in the genus Propithecus Malagasey Lemur. Journal of Human Evolution. 1, 379-388.

Post, P.W., Szabó, G., Keeling, M.E., 1975. A quantitative and morphological study of the pigmentary system of the chimpanzee with the light and electron microscope. American Journal of Physical Anthropology. 43, 435-443.

Rakotonirina, H., Kappeler, P.M., Fichtel, C., 2017. Evolution of facial color pattern complexity in lemurs. Scientific Reports. 7, 1-11.

Rakotonirina, L.H.F., Randriantsara, F., Rakotoarisoa, A.H., Rakotondrabe, R., Razafindramanana, J., Ratsimbazafy, J., King, T., 2014. A preliminary assessment of sifaka (propithecus) distribution, chromatic variation and conservation in Western Central Madagascar. Primate Conservation. 28, 43-53.

Ramírez-Delgado, V.H., Sanabria-Urbán, S., Serrano-Meneses, M.A., Cueva del Castillo, R., 2016. The converse to Bergmann's rule in bumblebees, a phylogenetic approach. Ecology and Evolution. 6, 6160-6169.

Revell, L.J., Harmon, L.J., Collar, D.C., 2008. Phylogenetic signal, evolutionary process, and rate. Systematic biology. 57, 591-601.

Rowe, N., 1996. The pictoral guide to the living primates. Pagonias Press, East Hampton.

Sambrook, J., Fritch, E., Maniatus, T., 1989. Molecular cloning: a laboratory manual., 2nd ed. ed. Cold Spring Harbor Press, New York.

Sandel, A.A., 2013. Brief communication: Hair density and body mass in mammals and the evolution of human hairlessness. American Journal of Physical Anthropology. 152, 145150.

Santana, S.E., Alfaro, J.L., Noonan, A., Alfaro, M.E., 2013. Adaptive response to sociality and 
ecology drives the diversification of facial colour patterns in catarrhines. Nature

$$
\text { Communications. 4, 1-7. }
$$

714 Santana, S.E., Lynch Alfaro, J., Alfaro, M.E., 2012. Adaptive evolution of facial colour patterns 715 in Neotropical primates. Proceedings. Biological sciences / The Royal Society. 279, 220411.

717

718

719

720

721

722

723

724

725

726

727

728

729

730

731

732

Schmidt, M., 2011. Locomotion and postural behaviour. Advances in Science and Research. 5, $23-39$.

Schwartz, G.G., Rosenblum, L.A., 1981. Allometry of primate hair density and the evolution of human hairlessness. American Journal of Physical Anthropology. 55, 9-12.

Seibert, H.C., Steggerda, M., 1999. The Size and Shape of human head hair - Along Its Shaft. The Journal of Heredity. 302-304.

Shearer, C.L., Ezenwa, V.O., 2020. Rainfall as a driver of seasonality in parasitism. International Journal for Parasitology: Parasites and Wildlife. 12, 8-12.

Spriggs, A.N., 2017. Evolution of Lemur Color Evolution. University at Albany, State University of New York.

Steggerda, M., Seibert, H.C., 1941. Size and shape of head hair from six racial groups. Journal of Heredity. 32, 315-318.

Stevens, M., Párraga, C.A., Cuthill, I.C., Partridge, J.C., Troscianko, T.S., 2007. Using digital photography to study animal coloration. Biological Journal of the Linnean Society. 90, 211237.

Stevens, M., Stoddard, M.C., Higham, J.P., 2009. Studying primate color: towards visual systemdependent methods. International Journal of Primatology. 30, 893-917.

Sumner, P., Mollon, J.D., 2003. Colors of primate pelage and skin: Objective assessment of 
conspicuousness. American Journal of Primatology. 59, 67-91.

736

737

738

739

740

741

742

743

744

745

746

747

748

749

750

751

752

753

754

755

756

757
Surridge, A.K., Osorio, D., Mundy, N.I., 2003. Evolution and selection of trichromatic vision in primates. Trends in Ecology and Evolution. 18, 198-205.

Tapanes, Elizabeth, Kamilar, Jason M, Bradley, B.J., 2021. Molecular and Cellular Processes of Pelage Growth and Pigmentation in Primate Evolution. In: Evolutionary Cell Processes in Primates. pp. 1-33.

Tapanes, E., Irwin, M., Spriggs, Amanda Nicole, Kamilar, Jason M., Bradley, B.J., 2018. Subtle sexual dichromatism and dimorphism detected in wild Propithecus diadema. In: The 87th Annual Meeting of the American Association of Physical Anthropologists.

Tattersall, I., 1986. Notes on the distribution and taxonomic status of some species of Propithecus In Madagascar. Folia Primatologica. 46, 51-63.

Villemereuil, P. de, Nakagawa, S., 2014. General quantitative genetic methods for comparative biology. In: Modern Phylogenetic Comparative Methods and Their Application in Evolutionary Biology. pp. 287-304.

Wheeler, P.E., 1985. The loss of functional body hair in man: the influence of thermal environment, body form and bipedality. Journal of Human Evolution. 14, 23-28.

Wheeler, P.E., 1992. The influence of the loss of functional body hair on the water budgets of early hominids. Journal of Human Evolution. 23, 379-388.

Winters, S., Allen, W., Higham, J., 2019. The structure of species discrimination signals across a primate radiation. $1-28$.

Xing, S., Bonebrake, T.C., Tang, C.C., Pickett, E.J., Cheng, W., Greenspan, S.E., Williams, S.E., Scheffers, B.R., 2016. Cool habitats support darker and bigger butterflies in Australian tropical forests. Ecology and Evolution. 6, 8062-8074. 


\section{Figures}
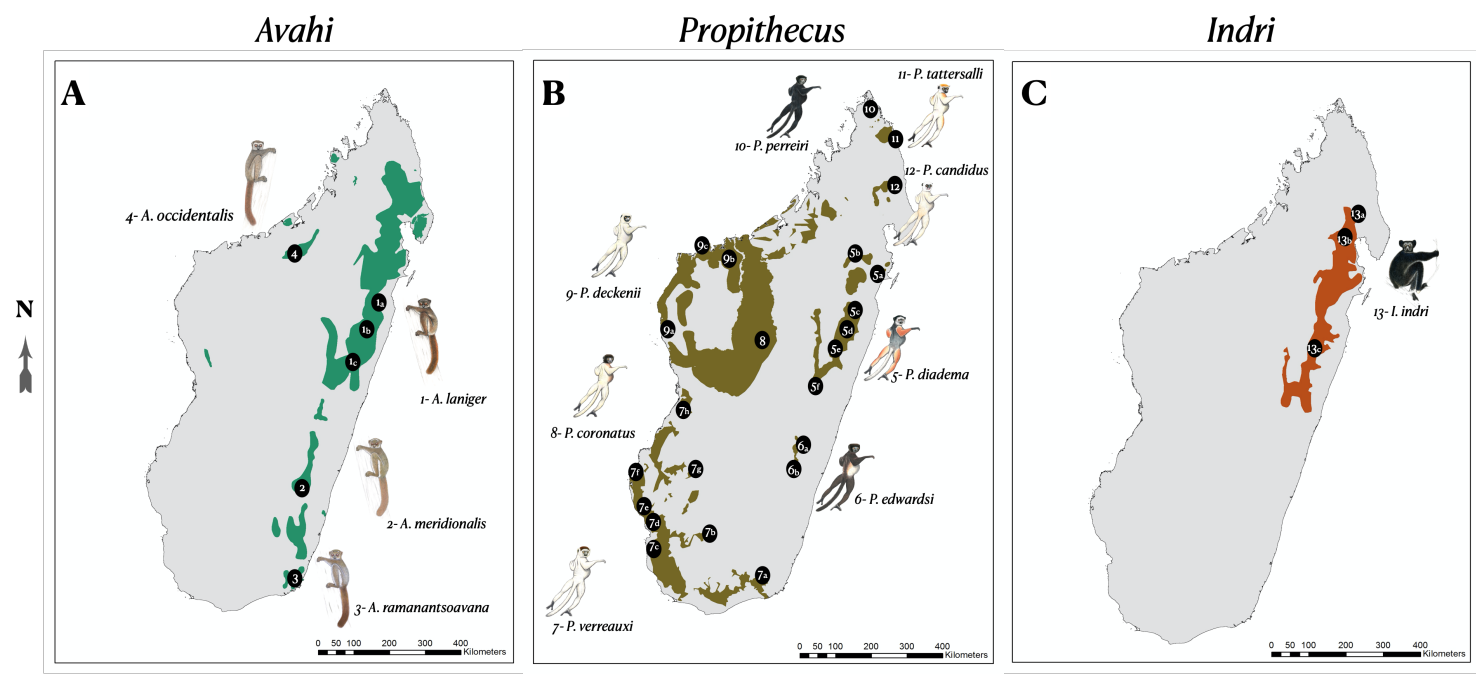

D
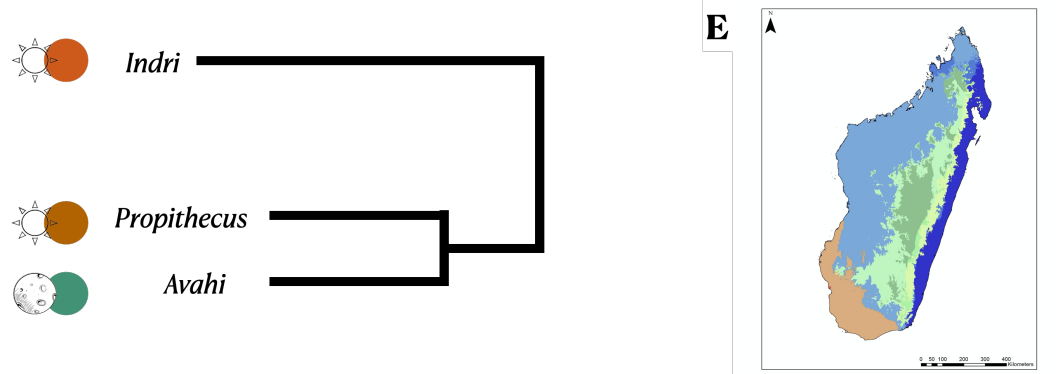

760

761

762

763

764

765

766

767

768

769

770

771

Figure 1 Indriidae species ranges and sampling localities for (A) Avahi, (B) Propithecus, and (C)

Indri; along with a (D) cladogram, and (E) Koppen-climate zones that span the genera's

\section{distribution.}

Key: Avahi spp. = (1a) Betampona, (1b) Sihanaka forest, (1c) Andasibe, (2) Forest west of Fort Dauphin, (3)

Vondrozo, (4) Ankarafatsika; Propithecus spp. = (5a) Betampona, (5b) Zahamahena, (5c) Didy, (5d) Sihanaka

forest, (5e) forest patch near Andasibe, (5f) Tsinjoarivo (eastern and western), (6a) Nandihizana, (6b) East of

Farohny River, (7a) Mandrare Valley, (7b) Bevala East, (7c) Tsinanampetsotsa, (7d) Lower Ifaty, (7e) Ifaty, (7f)

Lake Ihortry, (7g) Ankazoabo West, (7h) Upper Tsirbihina River, (8) Ambararatabe, (9a) Tsingy de Bemaraha, (9b)

Tsingy de Namoraka, (9c) Baie de Baly Nat Park, (10) Reserve of Analamerana, (11) Forest fragment near Daraina,

(12) Anjanaharibe-Sud Reserve; Indri indri = (13a) Anjanaharibe-Sud Reserve, (13b) 40 km West of Maroantsetra,

(13c) Sihanaka forest 

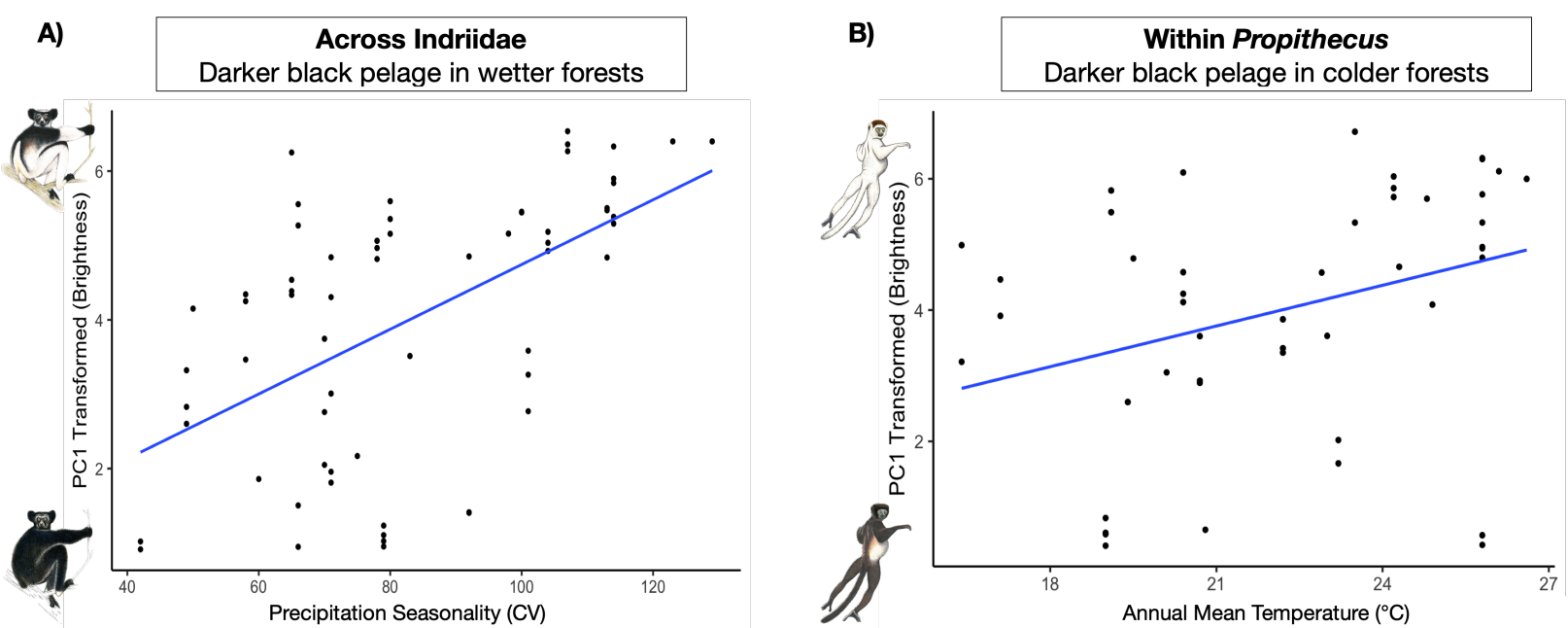

Figure 2 Plot of brightness across (A) the entire Indriidae family, in association with precipitation

Seasonality (CV) (showing adherence to Gloger's Rule), and (B) only within the Propithecus genus, in association with Annual Mean Temperature $\left({ }^{\circ} \mathrm{C}\right)$ (showing adherence to Bogert's Rule).

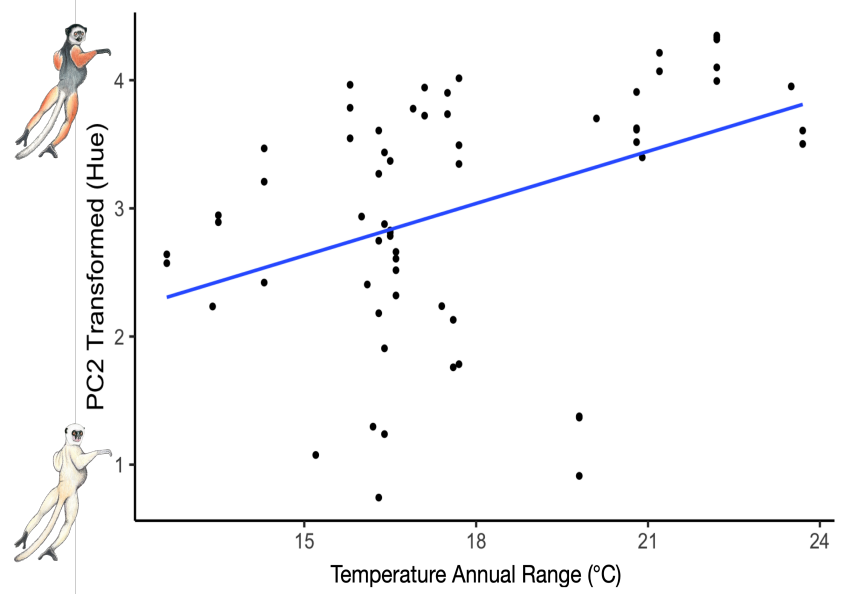

Figure 3 Plot of pelage hue trends across (A) the entire Indriidae family, in association with temperature annual range $\left({ }^{\circ} \mathrm{C}\right)$ (showing adherence to Gloger's Rule). Results are similar within Propithecus. 
793

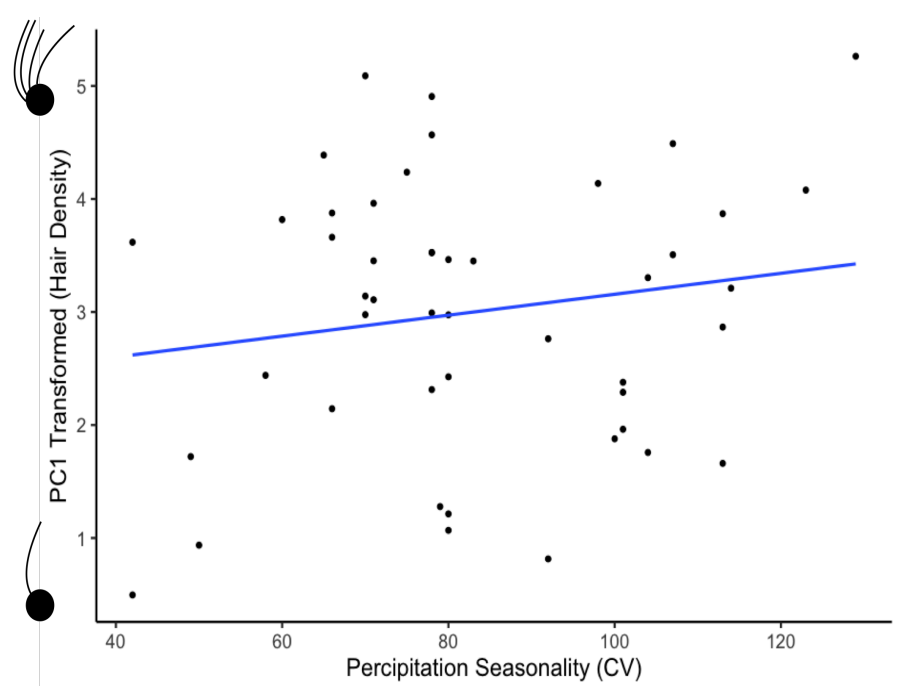

Figure 4 Plot of hair density trends. The relationship between PC1 and precipitation seasonality $(\mathrm{CV})$ is significantly associated with hair density on the limbs and crown across the Indriidae family. Lower PC1 values are associated with lower hair density on the limbs and crown.

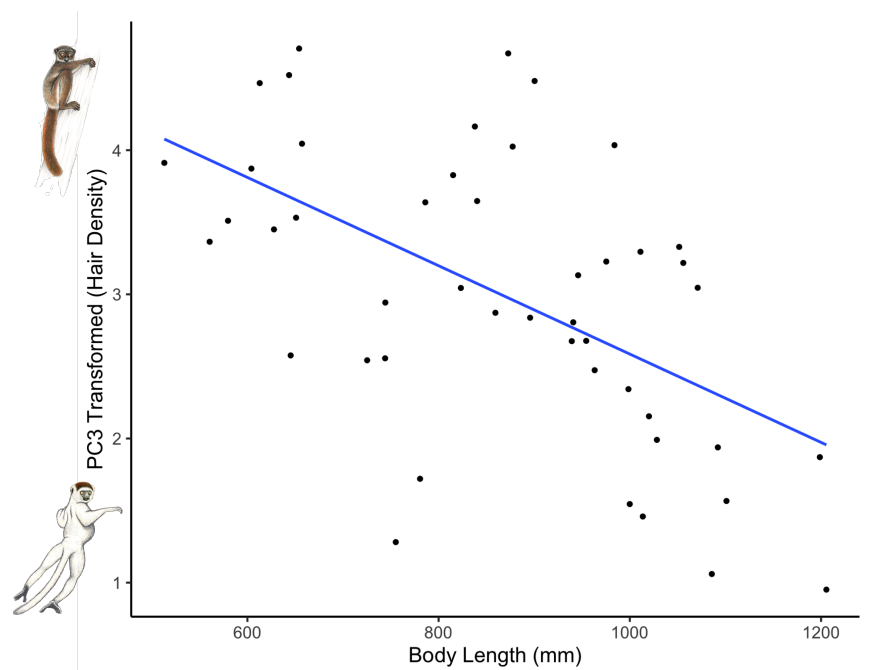

Figure 5 Plot of hair density trends. The relationship between PC3 and body length (capturing length, in $\mathrm{mm}$ ) is significantly associated with hair density on the dorsal torso across Indriidae. Lower PC3 values are associated with lower hair density across the dorsal torso. 
A

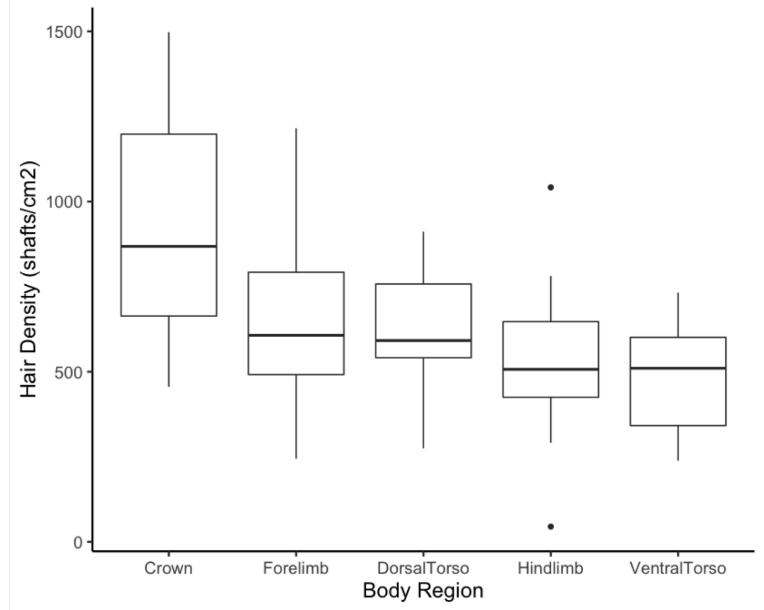

B

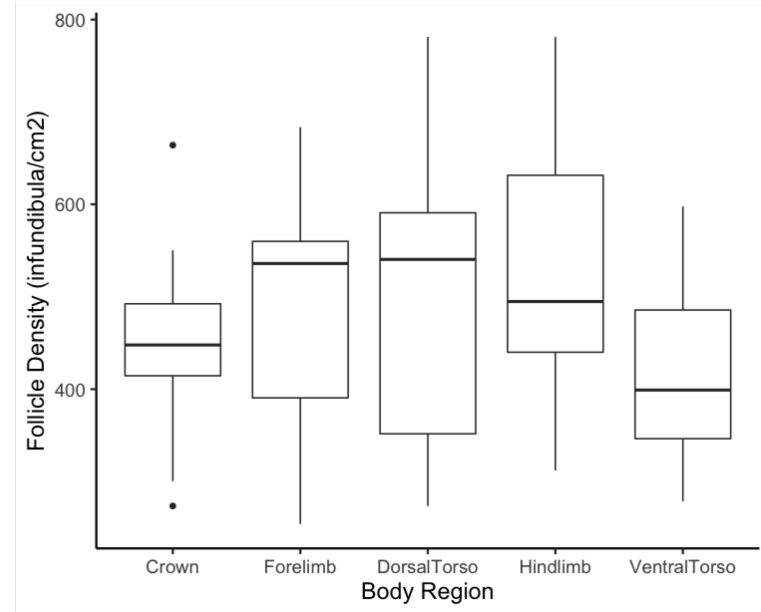

Figure 6 Boxplots illustrating variation in (A) hair density and (B) follicle density across body regions, for Indriidae. Black lines represent the average, and black dots represent outliers.

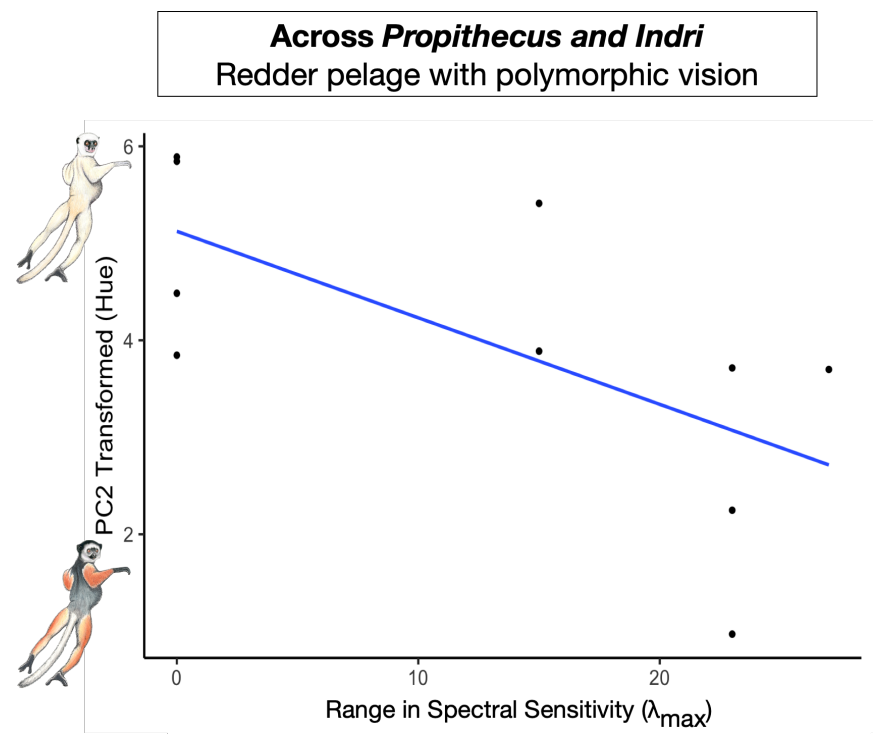

Figure 7 Plot of pelage hue trends across diurnal Propithecus and Indri genera, in association with the

812 range (i.e., difference) in opsin peak spectral sensitivity. 
814 Table 1 Results of PGLMMs predicting hair brightness (RGB averages) across all Indriidae taxa

815 and only within Propithecus

\begin{tabular}{cccccc} 
Variable & Mean Est. & Lower CI & Upper CI & ESS & P MCMC \\
\hline \multicolumn{2}{l}{ Across Indriidae $\left(\mathrm{PC} 1 ; \mathrm{H}^{2}=0.700\right)$} & & & & \\
\hline Intercept & -5.914 & -16.017 & 4.438 & 9,000 & 0.251 \\
BIO01 & -0.543 & -1.491 & 0.405 & 9,295 & 0.254 \\
BIO04 & 0.896 & -0.523 & 2.315 & 9,000 & 0.216 \\
BIO07 & -0.388 & -2.179 & 1.459 & 9,000 & 0.670 \\
BIO13 & 0.297 & -0.179 & 0.772 & 9,000 & 0.203 \\
BIO15 & 0.728 & 0.034 & 1.484 & 9,000 & $\mathbf{0 . 0 5 0}$ \\
Body size & 0.011 & -0.722 & 0.723 & 9,000 & 0.980 \\
\hline Within Propithecus $\left(\mathrm{PC} ; ; \mathrm{H}^{2}=0.902\right)$ & & & \\
\hline Intercept & 0.675 & -8.993 & 10.320 & 9,000 & 0.886 \\
BIO01 & -1.303 & -2.068 & -0.578 & 9,000 & $\mathbf{0 . 0 0 2}$ \\
BIO04 & -0.489 & -1.904 & 0.931 & 9,000 & 0.491 \\
BIO07 & 0.592 & -1.024 & 2.088 & 9,000 & 0.444 \\
BIO13 & 0.002 & -0.439 & 0.398 & 9,000 & 0.981 \\
BIO15 & 0.362 & -0.304 & 0.981 & 9,000 & 0.274 \\
Body size & 0.531 & -0.061 & 1.106 & 9,000 & $0.074 !$ \\
\hline
\end{tabular}

816

Bold values indicate $\mathrm{p}<0.05$, ' indicates $\mathrm{p}<0.10, \mathrm{H}^{2}$ is akin to phylogenetic signal

817

818

819

820

821

822

823

824

825

826

827

828 
829 Table 2 Results of PGLMMs predicting hair hue (RG ratio values) across all Indriidae taxa

\begin{tabular}{cccccc} 
Variable & Mean Est. & Lower CI & Upper CI & ESS & P MCMC \\
\hline PC1; H ${ }^{2}=0.667$ & & & & & \\
\hline Intercept & -6.005 & -16.249 & 4.025 & 9,114 & 0.243 \\
BIO01 & -0.529 & -1.484 & 0.400 & 9,000 & 0.268 \\
BIO04 & 0.903 & -0.436 & 2.379 & 9,000 & 0.210 \\
BIO07 & -0.377 & -2.242 & 1.335 & 9,000 & 0.676 \\
BIO13 & 0.298 & -0.159 & 0.770 & 8,684 & 0.216 \\
BIO15 & 0.722 & -0.015 & 1.413 & 9,000 & $0.051 !$ \\
Body size & 0.012 & -0.689 & 0.746 & 9,000 & 0.970 \\
\hline PC2; H $=0.530$ & & & & & \\
\hline Intercept & 3.081 & -5.331 & 11.610 & 9,000 & 0.480 \\
BIO01 & 0.187 & -0.619 & 1.046 & 9,000 & 0.657 \\
BIO04 & -0.960 & -2.143 & 0.220 & 9,000 & 0.103 \\
BIO07 & 1.675 & 0.222 & 3.195 & 9,000 & $\mathbf{0 . 0 2 6}$ \\
BIO13 & -0.212 & -0.592 & 0.168 & 8,953 & 0.258 \\
BIO15 & -0.486 & -1.083 & 0.115 & 9,000 & 0.112 \\
Body size & 0.155 & -0.462 & 0.750 & 9,000 & 06.09 \\
\hline Bol
\end{tabular}

830 Bold values indicate significance below 0.05, ! indicates $\mathrm{p}<0.10, \mathrm{H}^{2}$ is akin to phylogenetic

831 signal.

832

833

834

835 
836 Table 3 Results of PGLMMs predicting hair hue (RG ratio values) within the Propithecus genus

\begin{tabular}{cccccc} 
Variable & Mean Est. & Lower CI & Upper CI & ESS & P MCMC \\
\hline PC1; H ${ }^{2}=0.637$ & & & & \\
\hline Intercept & -0.552 & -18.757 & 18.397 & 9,347 & 0.956 \\
BIO01 & -0.021 & -2.034 & 1.851 & 9,000 & 0.974 \\
BIO04 & -0.403 & -2.744 & 2.072 & 9,000 & 0.705 \\
BIO07 & 0.109 & -3.216 & 3.227 & 9,000 & 0.927 \\
BIO13 & -0.252 & -1.118 & 0.599 & 9,000 & 0.549 \\
BIO15 & 0.571 & -0.989 & 2.057 & 9,000 & 0.461 \\
Body size & 0.381 & -1.260 & 1.926 & 9,357 & 0.637 \\
\hline PC2; H $=0.520$ & & & & \\
\hline Intercept & 1.839 & -7.905 & 11.710 & 9,000 & 0.714 \\
BIO01 & 1.432 & 0.492 & 2.392 & 9,000 & $\mathbf{0 . 0 0 4}$ \\
BIO04 & -1.223 & -2.593 & 0.164 & 9,000 & $0.079 !$ \\
BIO07 & 1.158 & -0.672 & 2.878 & 9,000 & 0.195 \\
BIO13 & -0.450 & -0.881 & 0.018 & 9,000 & $\mathbf{0 . 0 4 8}$ \\
BIO15 & -1.092 & -1.870 & -0.319 & 9,000 & $\mathbf{0 . 0 0 8}$ \\
Body size & 0.801 & 0.074 & 1.547 & 9,000 & $\mathbf{0 . 0 3 4}$ \\
\hline PC3; H ${ }^{2}=0.224$ & & & & \\
\hline Intercept & 3.427 & -10.922 & 19.147 & 9,000 & 0.618 \\
BIO01 & -0.430 & -2.037 & 1.143 & 9,000 & 0.583 \\
BIO04 & 0.135 & -1.603 & 2.164 & 9,000 & 0.932 \\
BIO07 & -0.739 & -3.181 & 1.703 & 9,000 & 0.551 \\
BIO13 & -0.011 & -0.701 & 0.618 & 9,000 & 0.963 \\
BIO15 & -0.015 & -1.168 & 1.230 & 9,000 & 0.971 \\
Body size & -0.151 & -1.192 & 1.435 & 9,000 & 0.828 \\
\hline Bold & & &
\end{tabular}

837 Bold values indicate significance below 0.05 , ! indicates $\mathrm{p}<0.10, \mathrm{H}^{2}$ is akin to phylogenetic

838 signal.

839

840

841

842

843

844

845

846

847 
848 Table 4 Results of PGLMMs predicting hair and follicle density across all Indriidae taxa

\begin{tabular}{cccccc} 
Variable & Mean Est. & Lower CI & Upper CI & ESS & P MCMC \\
\hline PC1; H ${ }^{2}=0.222$ & & & & \\
\hline Intercept & -6.478 & -22.987 & 18.456 & 9,456 & 0.401 \\
BIO01 & -0.036 & -1.368 & 1.366 & 9,000 & 0.961 \\
BIO04 & 0.770 & -0.673 & 2.228 & 9,000 & 0.278 \\
BIO07 & -1.093 & -3.262 & 1.047 & 9,434 & 0.314 \\
BIO13 & 0.523 & -0.085 & 1.190 & 9,000 & 0.101 \\
BIO15 & 1.232 & 0.185 & 2.255 & 9,290 & $\mathbf{0 . 0 2 0}$ \\
Body size & -0.275 & -1.326 & 0.770 & 9,339 & 0.597 \\
\hline PC2; H $=0.217$ & & & & \\
\hline Intercept & 0.256 & -15.042 & 16.829 & 9,000 & 0.981 \\
BIO01 & 0.175 & -1.238 & 1.587 & 9,000 & 0.812 \\
BIO04 & 0.150 & -1.334 & 1.643 & 9,000 & 0.835 \\
BIO07 & -0.990 & -3.299 & 1.243 & 9,000 & 0.375 \\
BIO13 & 0.110 & -0.523 & 0.806 & 9,000 & 0.736 \\
BIO15 & 0.518 & -0.550 & 1.585 & 9,765 & 0.331 \\
Body size & -0.161 & -1.266 & 0.922 & 8,309 & 0.760 \\
\hline PC3; H ${ }^{2}=0.330$ & & & & \\
\hline Intercept & 10.259 & -0.399 & 20.576 & 9,000 & $0.057 !$ \\
BIO01 & -0.259 & -1.175 & 0.700 & 9,000 & 0.602 \\
BIO04 & 0.071 & -0.953 & 1.056 & 9,307 & 0.876 \\
BIO07 & -0.129 & -1.643 & 1.413 & 9,000 & 0.853 \\
BIO13 & -0.337 & -0.772 & 0.081 & 9,000 & 0.123 \\
BIO15 & 0.438 & -0.276 & 1.164 & 9,908 & 0.228 \\
Body size & -1.265 & -2.012 & -0.514 & 9,000 & $\mathbf{0 . 0 0 2}$ \\
\hline Bo & & &
\end{tabular}

849 Bold values indicate significance below 0.05 , ' indicates $\mathrm{p}<0.10, \mathrm{H}^{2}$ is akin to phylogenetic signal.

850

851 
852 Table 5 Summary of ANOVA examining hair and follicle density variation across distinct body

853 regions for Indriidae

\section{DF Sum Sq. Mean Sq. F value P value}

Hair density

\begin{tabular}{cccccc}
\hline Body Region & 4 & 1458536 & 364634 & 5.808 & $<\mathbf{0 . 0 0 0 1}$ \\
Residuals & 60 & 3766879 & 62781 & & \\
\hline Follicle density & & & & & \\
\hline Body Region & 4 & 108592 & 27148 & 1.524 & 0.207 \\
Residuals & 60 & 1068659 & 17811 & &
\end{tabular}

854 
Table 6 Results of PGLMMs predicting hair and follicle density within the Propithecus genus

\begin{tabular}{|c|c|c|c|c|c|}
\hline Variable & Mean Est. & Lower CI & Upper CI & ESS & P MCMC \\
\hline \multicolumn{6}{|c|}{$\mathrm{PC} 1 ; \mathrm{H}^{2}=0.270$} \\
\hline Intercept & 8.876 & -9.863 & 26.645 & 9,000 & 0.315 \\
\hline BIO01 & 1.116 & -0.473 & 2.668 & 9,280 & 0.160 \\
\hline BIO04 & 0.032 & -1.716 & 1.724 & 7,868 & 0.987 \\
\hline BIO07 & 0.562 & -2.273 & 3.088 & 9,000 & 0.671 \\
\hline BIO13 & -0.113 & -0.798 & 0.580 & 8,822 & 0.746 \\
\hline BIO15 & -0.796 & -1.978 & 0.296 & 9,000 & 0.167 \\
\hline Body size & -1.173 & -2.607 & 0.333 & 9,000 & 0.111 \\
\hline \multicolumn{6}{|c|}{$\mathrm{PC} 2 ; \mathrm{H}^{2}=0.190$} \\
\hline Intercept & 9.252 & -17.259 & 37.827 & 9,000 & 0.494 \\
\hline BIO01 & 1.437 & -0.749 & 3.688 & 9,000 & 0.192 \\
\hline $\mathrm{BIO} 04$ & 0.351 & -2.135 & 2.597 & 9,000 & 0.760 \\
\hline $\mathrm{BIO} 07$ & -0.042 & -3.693 & 3.627 & 9,571 & 0.988 \\
\hline $\mathrm{BIO} 13$ & -0.090 & -1.141 & 0.898 & 9,356 & 0.862 \\
\hline BIO15 & -0.508 & -2.082 & 1.157 & 9,000 & 0.530 \\
\hline Body size & -1.632 & -3.695 & 0.666 & 9,000 & 0.134 \\
\hline \multicolumn{6}{|c|}{$\mathrm{PC} 3 ; \mathrm{H}^{2}=0.279$} \\
\hline Intercept & -12.391 & -31.523 & 5.691 & 9,000 & 0.186 \\
\hline BIO01 & 0.766 & -0.815 & 2.345 & 9,000 & 0.330 \\
\hline BIO04 & 1.090 & -0.802 & 2.988 & 9,000 & 0.224 \\
\hline BIO07 & -1.264 & -4.442 & 1.564 & 9,000 & 0.382 \\
\hline BIO13 & 0.437 & -0.282 & 1.117 & 9,000 & 0.219 \\
\hline BIO15 & 0.309 & -0.864 & 1.559 & 9,000 & 0.606 \\
\hline Body size & 0.738 & -0.698 & 2.194 & 9,000 & 0.310 \\
\hline
\end{tabular}

871 Bold values indicate significance below 0.05 , ' indicates $\mathrm{p}<0.10, \mathrm{H}^{2}$ is akin to phylogenetic signal.

872

873

874

875

876

877

878

879

880

881

882

883

884

885

886

887

888 
889 Table 7 Summary of linear models examining pelage coloration against difference in opsin peak

890 spectral sensitivity, using hue (PC1) scores of individuals across a subset of 10 sampling

891 locations

Estimate Std. Error T value P value

\begin{tabular}{ccccc}
\hline PC1 & & & & \\
\hline [Intercept] & -1.529 & 1.611 & -0.949 & 0.374 \\
Difference in Spectral Sensitivity & -0.234 & 0.089 & -2.630 & $\mathbf{0 . 0 3 4}$ \\
Number of Opsin Alleles & 2.635 & 1.501 & 1.746 & 0.124
\end{tabular}

892 SE: 1.05 on 7 degrees of freedom; $\mathrm{R}^{2}=0.516, \mathrm{~F}=5.801$ on 2 and 7 degrees of freedom; $\mathrm{p}=0.033$. Bold values

893 indicate significance below 0.05 .

894

895

896

897 